\title{
Overexpression of miR-450 affects the biological behavior of HepG2 cells by targeting DNMT3a
}

This article was published in the following Dove Press journal: OncoTargets and Therapy

\author{
Yan Wang ${ }^{1}, *$ \\ Lina Wang ${ }^{2, *}$ \\ Xue $\mathrm{Yu}^{3}$ \\ Jianping Duan ${ }^{4}$ \\ 'Chronic Disease Management Center, \\ Qingdao Sixth People's Hospital, Qingdao \\ City, Shandong Province 266033, People's \\ Republic of China; ${ }^{2}$ Department of \\ Clinical Lab, Qingdao Sixth People's \\ Hospital, Qingdao City, Shandong \\ Province 266033, People's Republic of \\ China; ${ }^{3}$ Department of Nursing, Qingdao \\ Sixth People's Hospital, Qingdao City, \\ Shandong Province 266033, People's \\ Republic of China; ${ }^{4}$ Department of \\ Infectious Disease, Qingdao Sixth \\ People's Hospital, Qingdao City, \\ Shandong Province 266033, People's \\ Republic of China \\ *These authors contributed equally to \\ this work
}

Purpose: This study was designed to explore the regulation mechanism of miR-450 in the development of hepatocarcinoma, and the effects of overexpression of miR-450 on biological behaviors such as proliferation, migration, and invasion of hepatoma cells.

Methods: HepG2 cells were divided into miR-450 mimics group, miR-450 inhibitor group, miR-450 mimics NC group, miR-450 inhibitor NC group, and blank group. MTT assay was served to measure cell proliferation, and Transwell assay was used to test cell migration and invasion. Additionally, cell cycle was detected by flow cytometry and apoptosis was examined with AnnexinV-PI double staining. After the target gene of miR-450 was predicted by bioinformatics software, Western blot and dual luciferase reporter gene experiment were applied to verify the relationship between miR-450 and target gene.

Results: The MTT and Transwell assay indicated that overexpression of miR-450 inhibited the proliferation, invasion, and migration of HepG2 cells. The flow cytometry analysis showed that overexpression of miR-450 arrested the cell cycle in the G1 phase. Meanwhile, Annexin V-PI double staining assay revealed that overexpression of miR-450 promoted apoptosis of HepG2 cells. However, silencing miR-450 in HepG2 cells promoted proliferation and invasion, and reduced apoptosis. Moreover, we found that DNMT3a was the target gene of miR-450.

Conclusions: miR-450 could inhibit proliferation, invasion, and migration via regulating DNMT3a in hepatocarcinoma cells, which provided a theoretical basis for the treatment of liver cancer.

Keywords: miR-450, HepG2 cells, DNMT3a, proliferation, invasion

\section{Introduction}

Liver cancer is an extremely ordinary type of cancer, hich accounts for about $90 \%$ of all cases of primary liver cancer with more than 700,000 deaths each year. ${ }^{1-3}$ Hepatitis C or hepatitis B virus, alcohol, and metabolic disorders are major causes of liver cancer. ${ }^{3,4}$ Most cases of liver cancer could be prevented by vaccination, antiviral therapy, safe blood transfusion and injection procedures, and interventions to reduce excessive alcohol consumption. ${ }^{5}$ However, due to lack of drugs for targeting critical dependencies, the treatment of liver cancer is still needed for further research. ${ }^{6}$ In recent years, many cancer treatments have been based on small non-coding RNAs. Moreover, microRNA molecules play a key role in cancer development by regulating gene expression.

MicroRNAs are small types of non-coding RNAs that adjust the expression of target genes under physiological and pathophysiological conditions. Over time, many studies have evaluated the function of miRNAs in the progression of liver
Correspondence: Jianping Duan Department of Infectious Disease, Qingdao Sixth People's Hospital, No. 9, Fushun Road, Shibei District, Qingdao City, Shandong Province 266033, People's Republic of China

Tel +86 I 5653257812

Email duanjianping2019@163.com 
cancer. For example, miR-375 and miR-221 could be used as possible biomarkers to guide liver cancer treatment and to estimate prognosis. ${ }^{7}$ Besides, Wang et $\mathrm{al}^{8}$ have found that miR-876-5p could inhibit the proliferation and migration of HCC cells by regulating DNMT3a, and the progression of $\mathrm{HCC}$ is also slowed. Qian et al indicate that miR-30b-5p inhibits cell proliferation by mediating DNMT3a and slows down the cell cycle. ${ }^{9}$ Another study has shown that miR-34a in HCC tissues is silenced by downregulating DNMT3a. ${ }^{10}$ It could be speculated that DNMT3 might regulate the expression of multiple small molecules and participate in the development of liver cancer.

MiR-450, as a tumor inhibitor of multiple cancers, has been reported in breast cancer, colorectal cancer, ovarian cancer, and lung adenocarcinoma. ${ }^{11-14}$ However, the mechanism of action of miR-450 on liver cancer cells is still unclear. Fortunately, a study has shown that miR-450a targeted DNMT3. ${ }^{15}$ In the circumstances, we found that miR-450 suppressed HepG2 cell proliferation and invasion and promoted apoptosis and could target DNMT3a.

\section{Materials and methods}

\section{Cell grouping and transfection}

HepG2 cells were bought from Chinese Academy of Sciences cell bank. The cells were cultured in DMEM medium (Thermo Fisher Scientific, Waltham, MA, USA) containing $5 \% \mathrm{FBS}$, and incubated at $37^{\circ} \mathrm{C}$ with $5 \% \mathrm{CO}_{2}$. Cultured cells were divided into miR-450 mimics group, miR-450 inhibitor group, miR-450 mimics NC group, miR-450 inhibitor NC group andblank group and transfected with miR-450 mimics, miR-450 inhibitor miR-450 mimics NC, miR-450 inhibitor NC, and no treatment was done, respectively. Cell transfection was performed according to the lipofectamine ${ }^{\mathrm{TM}} 2000$ (Thermo Fisher Scientific, Waltham, MA, USA) transfection instructions. The successfully transfected HepG2 cells were prepared into cell suspensions using the same medium as in culture, and then inoculated in 24 -well plates with $1 \times 10^{5}$ cells/ well. Then, the cells were cultured in an incubator at $37^{\circ}$ C, $5 \% \mathrm{CO}_{2}$, and $95 \%$ humidity. miR-450 mimics, miR-450 inhibitor, mimics NC, and miR-450 inhibitor NC were synthesized by ThermoFisher scientific (Waltham, USA).

\section{qRT-PCR}

Total RNA from each group of cells was extracted by the TRIZOL kit (ThermoFisher scientific, MA, USA). QRT-PCR was conducted by applying ABI7500 quantitative PCR instrument (Applied Biosystems, USA). MiR-450 was amplified under the following conditions: primary reaction at $95^{\circ} \mathrm{C}$ for $10 \mathrm{mins}$, followed by reaction of $95^{\circ} \mathrm{C}$ for $10 \mathrm{~s}, 60^{\circ} \mathrm{C}$ for $20 \mathrm{~s}$, $72^{\circ} \mathrm{C}$ for $10 \mathrm{~s}, 40$ cycles. Simultaneously, DNMT3a was carried out using conditions of $95^{\circ} \mathrm{C}$ for $10 \mathrm{mins}$, followed by 40 cycles of $95^{\circ} \mathrm{C}$ for $15 \mathrm{~s}, 60^{\circ} \mathrm{C}$ for $1 \mathrm{~min}, 72^{\circ} \mathrm{C}$ for $10 \mathrm{~s}$. U6 and $\beta$-actin were served as the internal parameters of miR-450 and DNMT3a, respectively. The results were assessed by $2^{-\Delta \Delta C T}$ method. The primer sequence is shown in Table 1 .

\section{MTT assay}

In all group, 6 repeated wells were set in each group. Cell proliferation was tested at time points of 1, 2, 3, and 4 days using the MTT method. Twenty microliter MTT solutions were put into each well and incubated for $4 \mathrm{hrs}$. Then, 150 $\mu \mathrm{L}$ of DMSO solution (Sigma, St. Louis Missouri, USA) were put into each well, and cells were oscillated on a shaker for overnight. Optical density was measured by ELX800 microplate reader (Perkin Elmer, USA) at $490 \mathrm{~nm}$.

\section{Transwell assay}

The upper chamber was pre-coated with $50 \mu \mathrm{L}$ diluted Matrigel. Subsequently, DMEM containing 10\% fetal bovine serum was appended to the lower chamber. At the same time, approximately $1 \times 10^{5}$ HepG2 cells were seeded in the upper chamber. Next, HepG2 cells were cultured for 1 day in a foster box at $37^{\circ} \mathrm{C}$ and $5 \% \mathrm{CO}_{2}$. Cells on the lower layer of the membrane were fixed using $1 \%$ formaldehyde. After staining with crystal violet $(0.1 \%)$, cells on the upper layer of the membrane were gently rubbed out, while the cells in the lower layer of the membrane were examined under a microscope, and the numbers of invading cells were statistically calculated by randomly selecting five fields of view. Analogous application was applied to the

Table I Primer sequence of miR-450

\begin{tabular}{|l|l|}
\hline Primer & Sequences (5'-3') \\
\hline miR-450 & $\begin{array}{l}\text { F'-TTTTGCGATGTGTTCC } \\
\text { R'-GTGCAGGGTCCGAGGT }\end{array}$ \\
\hline U6 & $\begin{array}{l}\text { F'-CTCGCTTCGGCAGCACA } \\
\text { R'-AACGCTTCACGAATTTGCGT }\end{array}$ \\
\hline DNMT3a & $\begin{array}{l}\text { F'-CAATGACCTCTCCATCGTCAAC } \\
\text { R'-CATGCAGGAGGCGGTAGAA }\end{array}$ \\
\hline$\beta$-actin & F'-GAACGGTGAAGGTGACAG \\
& R'-TAGAGAGAAGTGGGGTGG \\
\hline
\end{tabular}


invasion assay, but there was no Matrigel in the upper chamber.

\section{Flow cytometry}

The cell cycle located in the transfected cells was detected using a Muse ${ }^{\mathrm{TM}}$ Cell Cycle reagent kit (EMD Millipore, USA). After transfection for 2 days, appropriate cells were centrifuged at room temperature, supernatant was discarded, and resuspended in PBS, then fixed in pre-cooled $70 \%$ ethanol. Muse ${ }^{\mathrm{TM}}$ Cell Cycle Reagent was put into the cell pellet and incubated at $25^{\circ} \mathrm{C}$ and dark for 30 mins. Subsequently, cell cycle was measured using MUSE Cell Analyzer (MUSETM, Merck Millipore, USA).

\section{AnnexinV-PI double staining assay}

After transfection for $48 \mathrm{hrs}$, HepG2 cells were transferred to a $1.5 \mathrm{~mL}$ centrifuge tube. Subsequently, $500 \mu \mathrm{L}$ binding buffer was used for suspension cells, and then $5 \mu \mathrm{L}$ Annexin V-EGFP and $5 \mu \mathrm{L}$ Propidium Iodide were added to the centrifuge tube. Finally, the cells were cultured at $25^{\circ} \mathrm{C}$ for 10 mins and then measured by flow cytometry (MUSETM, Merck Millipore, USA).

\section{Biological software predicts target genes of $\mathrm{miR}-450$}

The target genes of miR-450 were predicted by a variety of biological software, including TargetScan and MiRDB. The target gene that regulated miR-450 was selected within the crossover range. Finally, the DNA methyltransferase DNMT3a gene, which was involved in tumorigenesis and important signaling pathways, was selected as a candidate gene for regulation of miR-450.

\section{Western blot}

After transfection, cells were collected and lysed with protein extraction lysate on ice for 30 mins. Then, in succession, the lysate was centrifuged at $12,000 \mathrm{rpm}$ and $4^{\circ} \mathrm{C}$ for 10 mins. Supernatants were collected as protein samples. The protein was separated by SDS-PAGE, and then it was moved to PVDF membranes. Subsequently, PVDF membranes were blocked with $5 \%$ defatted milk powder-TBST, and then, membranes were incubated at $25^{\circ} \mathrm{C}$ for $2 \mathrm{hrs}$. After that, the membranes were incubated with mouse anti-human DNMT3a antibody $(1: 1,000$, Thermo Fisher Scientific, Waltham, USA) at $4^{\circ} \mathrm{C}$ overnight followed by incubated with HRP-labeled rabbit anti-mouse IgG secondary antibody (1:5,000, Kangwei Century Biotechnology Co., Ltd.,
Beijing, China) at $25^{\circ} \mathrm{C}$ for $1 \mathrm{hr} . \beta$-actin acted as the internal reference.

\section{Luciferase reporter gene assay}

HepG2 cells were performed to co-transfection by DNMT3a wild vector andmiR-450 mimics (mimic+wild group), miR-450 inhibitor (inhibitor+wild group), miR450 inhibitor $\mathrm{NC}$ (inhibitor $\mathrm{NC}+$ wild group), or miR-450 mimic NC (mimic NC+wild group). Meanwhile, HepG2 cells were conducted on co-transfection by DNMT3a mutation vector and miR-450 mimics (mimic+mutation group), miR-450 inhibitor (inhibitor+mutation group), miR-450 inhibitor $\mathrm{NC}$ (inhibitor $\mathrm{NC}+$ mutation group) or miR-450 mimic NC (mimic $\mathrm{NC}+$ mutation group). More importantly, all transfection plasmids were bought from Guangzhou RiboBio Co., Ltd (Guangzhou, China).

Total $100 \mu \mathrm{L}$ of Passive Lysis buffer was added to each well and lysed on a shaker at $25^{\circ} \mathrm{C}$ for $15 \mathrm{mins}$. After the cells were lysed, $20 \mu \mathrm{L}$ of each sample was transferred into a 96-well plate, and the relative activity of luciferase was calculated.

\section{Statistical analysis}

All data were represented by mean \pm SD. GraphPad Prism 5.0 software was applied to statistical analysis, and significance between groups was ascertained by one-way ANOVA compared with least significant difference. When the $P$-value was less 0.05 , the analysis was accepted as statistical difference.

\section{Results}

\section{The expression of miR-450}

Compared with blank group, miR-450 mimics NC group, and miR-450 inhibitor NC group, the level of miR-450 in miR-450 mimics group was greatly elevated, and in miR450 inhibitor group was obviously reduced $(P<0.01)$. There was not observably different of miR-450 expression between blank group, miR-450 mimics NC group, and miR-450 inhibitor NC group $(P>0.05)$ (Figure 1).

\section{Overexpression of miR-450 inhibited HepG2 cell proliferation, invasion, and migration}

We transfected miR-450 mimics or miR-450 inhibitor into HepG2 cells to upregulate or downregulate miR-450 expression. As shown in Figure 2, overexpression of miR-450 significantly inhibited the proliferation of HepG2 cells from the 


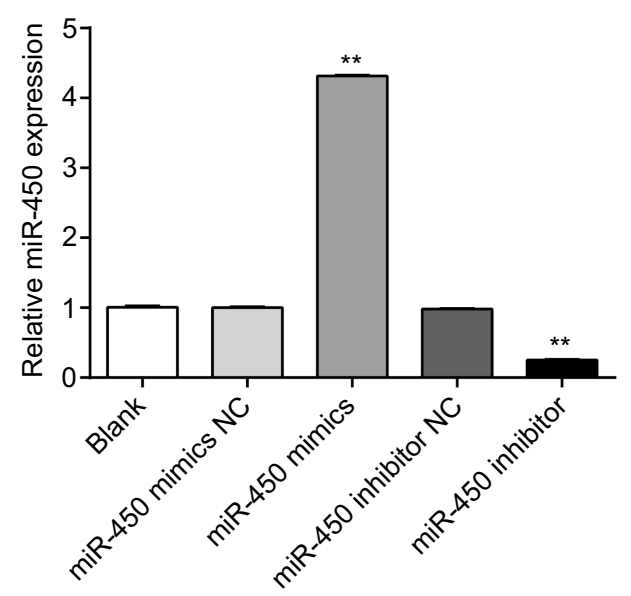

Figure I The expression levels of miR-450 in different groups. Note: $* * p<0.01$, versus blank, miR-450 mimics NC group or miR-450 inhibitor negative control (NC) group.

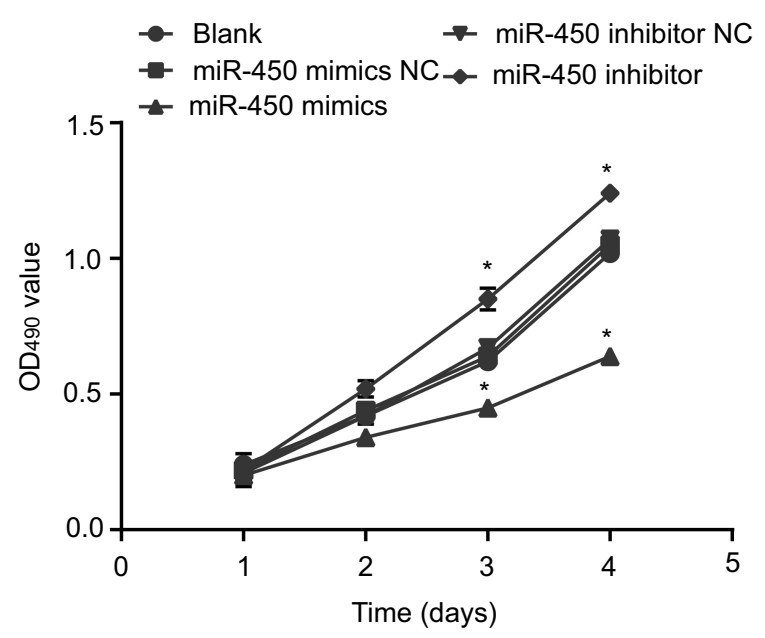

Figure 2 Effect of miR-450 on the proliferation of HepG2 cells. Note: $* P<0.05$, versus blank, miR-450 inhibitor NC or miR-450 mimics negative control (NC) groups.

third and fourth days, and knockdown of miR-450 significantly increased the proliferation of HepG2 cells $(P<0.05)$.

According to Transwell migration and Matrigel invasion assays, we found that the ability of migration and invasion of HepG2 cells in the miR-450 mimics group was remarkably lower than in the miR-450 mimics NC $(P<0.05$, Figure 3A and $\mathrm{B})$. Meanwhile, after miR-450 inhibitor exposure, the ability of migration of HepG2 cells was increased compared with the miR-450 inhibitor NC group $(P<0.05)$.

\section{Overexpression of miR-450 blocked HepG2 cell cycle in GI phase and promoted apoptosis}

Furthermore, we analyzed the cell cycle distribution in HepG2 cells after overexpression or knockdown of miR-450. The flow cytometry data showed that obviously higher cell component of the G0/G1 phase was exhibited in miR-450 mimics group than that of miR-450 mimics $\mathrm{NC}(P<0.05)$. However, the cells proportion in the $\mathrm{S}$ phase of miR-450 mimics group was lower than those in miR-450 mimics NC group $(P<0.05)$ (Figure 4A-B). Meanwhile, compared with miR-450 inhibitor $\mathrm{NC}$ group, the proportion of cells in the miR-450 inhibitor group was remarkably downregulated in the $\mathrm{G} 0 / \mathrm{G} 1$ phase and evidently upregulated in the $\mathrm{S}$ phase. There was no significant difference in the proportion of cells between miR-450 mimics NC group (or miR-450 inhibitor NC group) and blank group during the $\mathrm{G} 0 / \mathrm{G} 1, \mathrm{~S}$, and $\mathrm{G} 2 / \mathrm{M}$ phases. The results suggested that overexpression of miR-450 arrested the HepG2 cell cycle in G1 phase.

The results of flow cytometry indicated that overexpression of miR-450 increased the number of apoptosis of HepG2 cells, and inhibition of miR-450 expression reduced the number of apoptosis $(P<0.05$, Figure 5), which revealed that overexpression of miR-450 promoted apoptosis of HepG2 cells.

\section{DNMT3a was the target gene of miR-450}

UTR sequences were obtained through Target scan online database, and the results showed that the target site of DNMT3a and miR-450 was 3'-UTR region (Figure 6A). Then, luciferase assays were performed to further verify the association between miR-450 and DNMT3a. Results indicated that miR-450 overexpression significantly inhibited the luciferase activity of wild-type DNMT3a 3'-UTR, and miR-450 knockdown significantly increased the luciferase activity of wild-type DNMT3a 3'-UTR, whereas they had no influence on the luciferase activity of mutant DNMT3a 3'-UTR in HepG2 cells (Figure 6B). The expression of DNMT3a mRNA in the five groups was detected by qRTPCR. Distinctly lower DNMT3a gene expression of miR450 mimics group and evidently higher DNMT3a gene expression of miR-450 inhibitor group were found when compared with miR-450 mimics NC or miR-450 inhibitor $\mathrm{NC}$ group $(P<0.05$, Figure $6 \mathrm{C})$. Correspondingly, miR-450 overexpression prominently decreased DNMT3a protein expression and miR-450 inhibition remarkably increased DNMT3a protein expression in HepG2 cells as detected by Western blot $(P<0.05$, Figure 6D).

\section{Discussion}

Previous study has found that miR-450a could regulate the development of liver cancer by inhibiting the expression of DNMT3a, and miR-450a might be a useful agent for the 
A
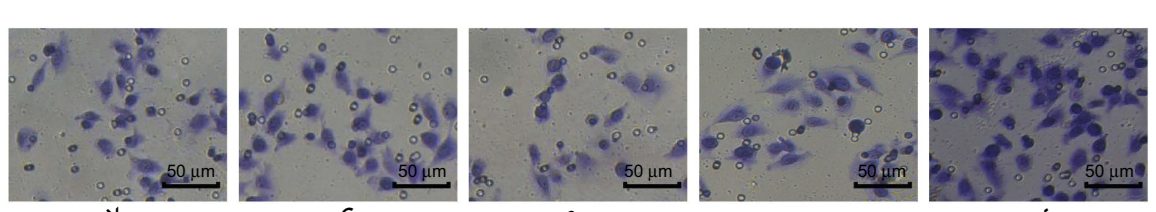

$8)^{2 r^{k}}$
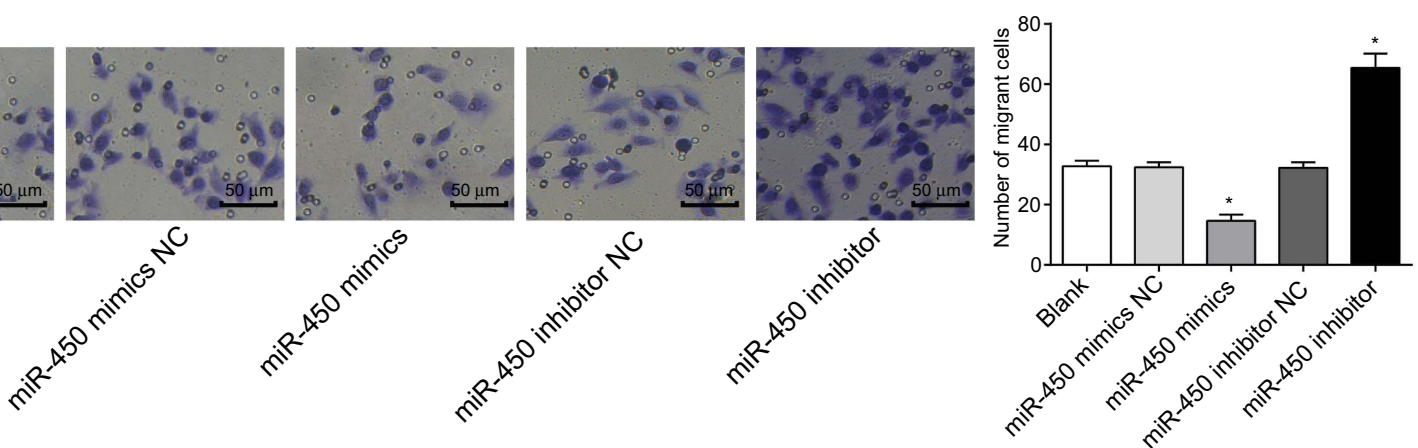

B
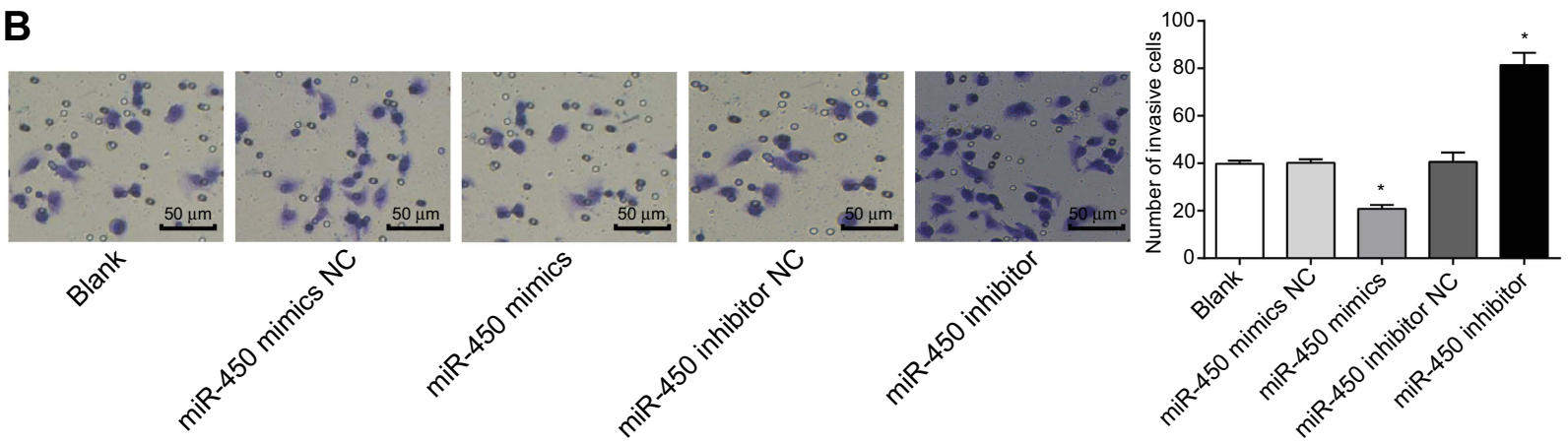

Figure 3 Overexpression of miR-450 inhibited invasion and migration of human hepatoma HepG2 cells. (A) Invasion of the cells in each group ( $\times 200)$ and the number of cells passing through the compartment in each group, (B) Transmembrane migration of cells in each group $(\times 200)$, and the number of cells passing through the compartment in each group. $* P<0.05$, versus blank, miR-450 inhibitor NC or miR-450 mimics negative control (NC) groups.

A
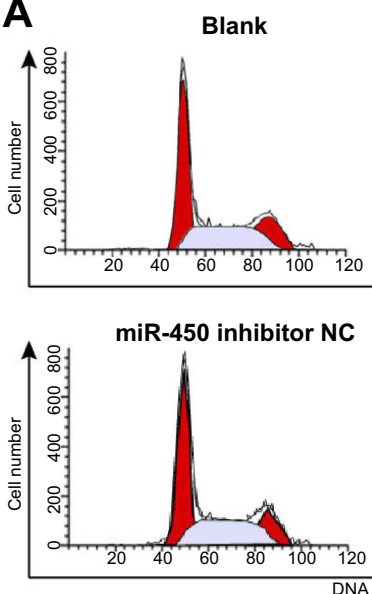

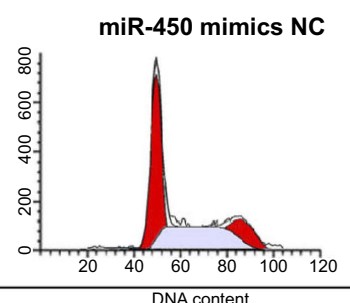

miR-450 inhibitor

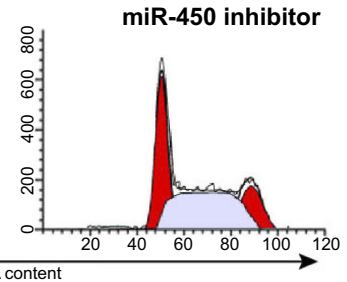

B

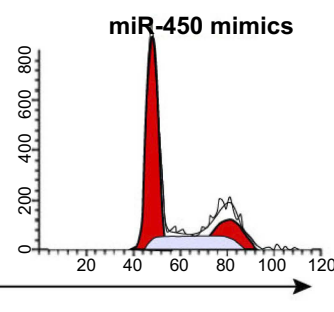

$\square$ Blank

$\square$ miR-450 inhibitor NC

$\square$ miR-450 mimics

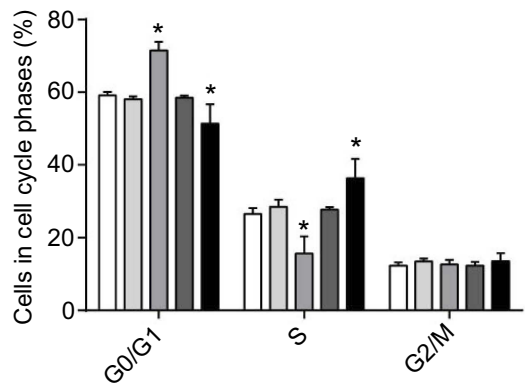

Figure 4 Effect of miR-450 overexpression or knockdown on the regulation of cell cycle in HepG2 cells. (A) The number of cells at different stages was examined with flow cytometry, (B) Cell proportion of each group at different stages. $* P<0.05$, versus blank, miR-450 inhibitor NC or miR-450 mimics negative control (NC) groups.

treatment of hepatocellular carcinoma. ${ }^{15}$ However, it is necessary to expand the number of downregulated miR$450 \mathrm{a}$ samples and explore the correlation between the expression of DNMT3a and miR-450a. In this research, based on previous studies, we focused on the downstream genes of miR-450 and studied the impacts of miR-450 on the biological processes of hepatoma cells. We found that overexpression of miR-450 arrested human hepatoma HepG2 cell cycle in G1 phase, restrained the cell proliferation, invasion and migration, and promoted cell apoptosis.

MiR-450a-3p could effectively inhibit the division of fertilized eggs when its mimetic fiber is injected into the fertilized egg. ${ }^{16}$ Moreover, miR-450a-3p blocks most 

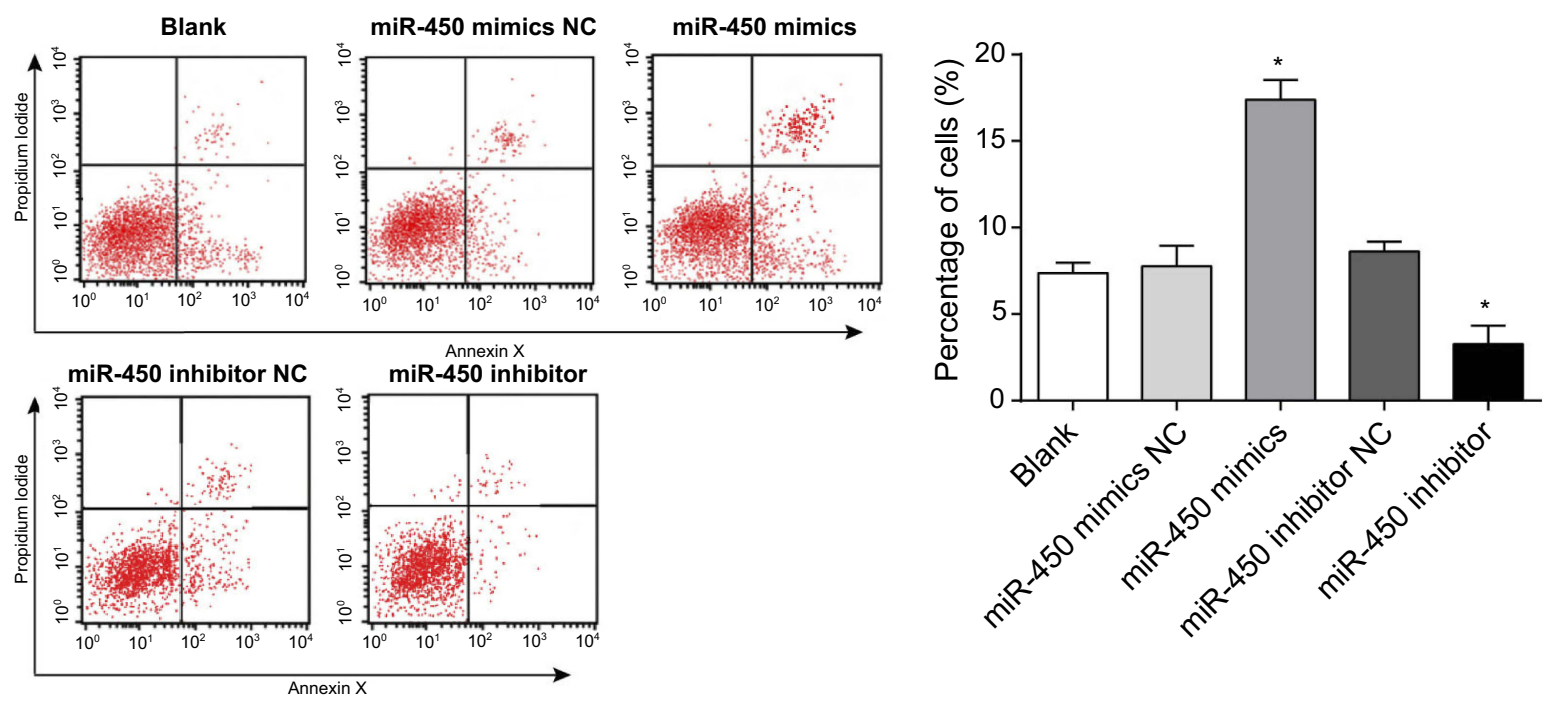

Figure 5 Effect of miR-450 overexpression or knockdown on apoptosis of HepG2 cells. Apoptotic cells in each group were checked by Annexin V-PI double staining. $* P<0.05$, versus blank, miR-450 inhibitor NC or miR-450 mimics negative control (NC) groups.

cells in the G1/G0 phase and inhibits cell proliferation. ${ }^{17}$ In addition, overexpression of miR-450a-5p could induce G1 arrest in cancer cells and negatively regulate the invasion and migration of ovarian tumor cells. ${ }^{18}$ Coincidentally, Liu et $\mathrm{al}^{19}$ have studied lung cancer cell lines and solid tumors, suggesting that lentiviral transfection carrying miR-450 could upregulate the expression of miR-450 and prominently reduce the invasion and multiplication of lung tumor cells. Properly, in this study, proliferation, migration, and invasion of liver cancer cells were inhibited by overexpression of miR-450, and apoptosis was promoted. Further, it was demonstrated that overexpression of miR-450 affected the biological characteristics of liver cancer cells.

Simultaneously, our studies provided evidence that miR-450 regulated the expression of DNMT3a in hepatocellular carcinoma cells (HCCs). It should be noted that DNMTs-mediated promoter hypermethylation is a major cause of epigenetic inactivation of tumor suppressor genes (TSGs). ${ }^{15}$ Moreover, the relationship between the expression of DNMT3a and hepatocellular carcinoma is also extensively studied. It has been shown that in non-cancerous liver tissues of chronic hepatitis or cirrhosis, the mRNA level of DNMT3a is substantially more than that of histologically healthy liver tissue, and even higher in HCC. ${ }^{20}$ Besides, Shikauchi et $\mathrm{al}^{21}$ have identified that SALL3 is induced by BMP-4 and silenced by the relevant DNMT3a in liver cancer.
Methylation of Septin9 mediated by DNMT3a also enhances liver fibrogenesis. ${ }^{22}$ Thus, it could be determined that DNMT3a could regulate the expression of multiple small molecules and participate in the progression of liver cancer.

In addition, DNMT3a acts as an intermediate and is targeted by miR-876-5p to inhibit the progression of hepatocellular carcinoma. ${ }^{8}$ Consumption of DNMT3a has been found to inhibit the proliferation of $\mathrm{HCCs}^{23}$ These findings indicate that regulating the expression of DNMT3a could reduce the proliferation of HCCs and slow down the progress of hepatocellular carcinoma. In the present research, overexpression of miR-450 inhibited DNMT3a levels, inhibited the multiplication of liver cancer cells. Moreover, during the development from normal liver, chronic hepatitis/cirrhosis to hepatic cellular cancer, the number of methylation genes and the expression of DNMT3a are gradually increased, and the development of liver cancer is positively correlated with the expression of DNMT3a. ${ }^{24}$ It is further shown that targeted inhibition of DNMT3a expression was an effective means of overexpressing miR-450 to inhibit proliferation of HCCs.

\section{Conclusions}

In conclusion, overexpression of miR-450 could inhibit the proliferation, migration, and invasion of HCCs and promote apoptosis by regulating expression of DNMT3a. 
A

\begin{tabular}{|c|c|c|c|c|c|c|c|}
\hline & $\begin{array}{l}\text { Predicted consequential pairing of target region (top) and } \\
\text { miRNA (bottom) }\end{array}$ & $\begin{array}{l}\text { Site } \\
\text { type }\end{array}$ & $\begin{array}{l}\text { Context+t } \\
\text { score }\end{array}$ & $\begin{array}{l}\text { Context++ score } \\
\text { percentile }\end{array}$ & \begin{tabular}{|} 
Weighted context++ \\
score
\end{tabular} & $\begin{array}{c}\text { Conserved branch } \\
\text { length }\end{array}$ & $\mathrm{P}_{\mathrm{cT}}$ \\
\hline $\begin{array}{l}\text { Position 1672-1678 of DNMT3A 3' UT } \\
\text { hsa-miR-450a-2-3p }\end{array}$ & 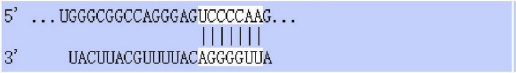 & $\begin{array}{c}\text { 7mer- } \\
\mathrm{m} 8\end{array}$ & -0.02 & 11 & -0.01 & 0 & \\
\hline
\end{tabular}

B

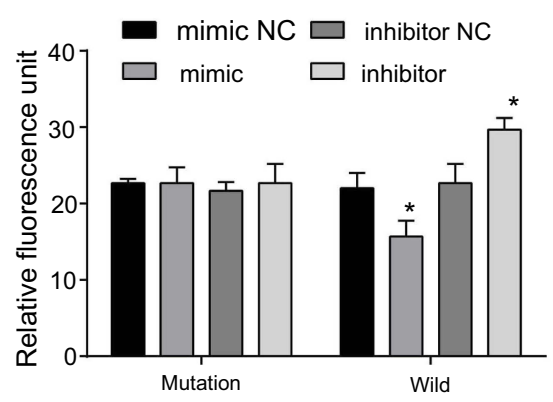

D

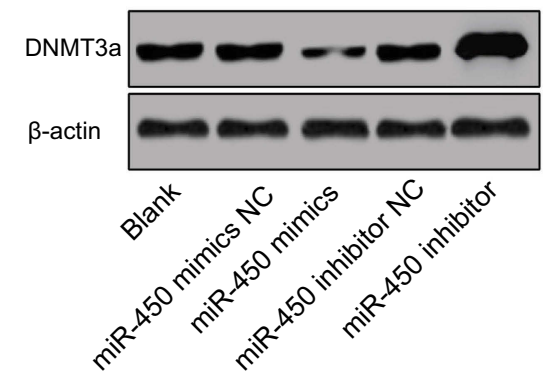

C
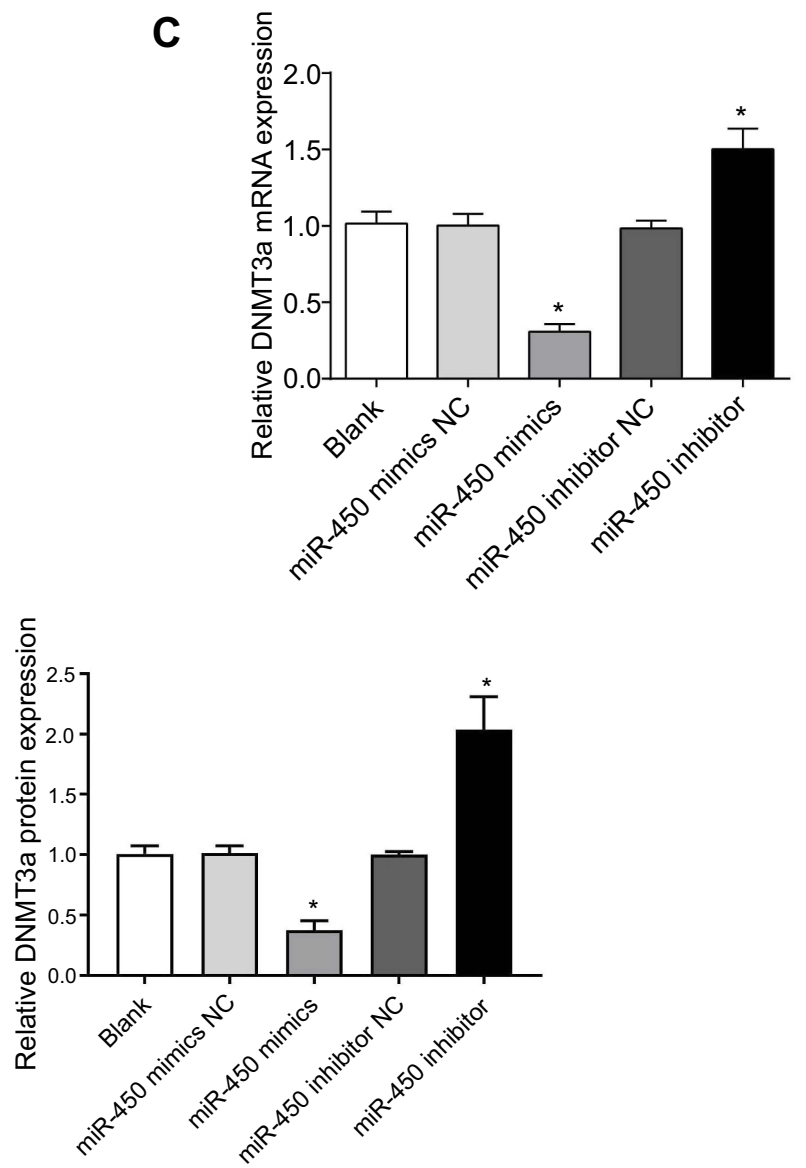

Figure 6 DNMT3a was the target gene of miR-450. (A) Target Scan ascertained target sites for DNMT3a and miR-450 binding, (B) Dual luciferase reporter gene activity assay, (C) DNMT3a mRNA expression in HepG2 cells was tested by qRT-PCR assay, (D) DNMT3a protein expression in HepG2 cells was checked by Western blot assay, $* P<0.05$, versus blank, miR-450 inhibitor NC or miR-450 mimics negative control (NC) groups.

MiR-450 could be a useful target for targeted therapy liver cancer.

\section{Ethics approval and consent to participate}

This study was conducted after obtaining local ethical committee approval of Qingdao Sixth People's Hospital. We confirm that all experiments were performed following relevant named institutional and national guidelines and regulations.

\section{Author contributions}

All authors contributed to data analysis, drafting or revising the article, gave final approval of the version to be published, and agree to be accountable for all aspects of the work.

\section{Disclosure}

The authors report no conflicts of interest in this work.

\section{References}

1. Ringehan M, Mckeating JA. Protzer U viral hepatitis and liver cancer. Philos Trans R Soc Lond B Biol Sci. 2017;372:20160274. doi:10.1098/ rstb.2016.0274

2. Affo S, Yu LX, Schwabe RF. The role of cancer-associated fibroblasts and fibrosisin. Liver Cancer. 2017;12(1):153-186.

3. Castelli G, Pelosi E. Testa U liver cancer: molecular characterization, clonal evolution and cancer stem cells. Cancers. 2017;5:E127. doi:10.3390/cancers 9090127

4. Lopane C, Agosti P, Gigante I, et al. Implications of the lysophosphatidic acid signaling axis in liver cancer. Biochim Biophys Acta. 2017; 1868:277-282.

5. Akinyemiju T, Abera S, Ahmed M, et al. The burden of primary liver cancer and underlying etiologies from 1990 to 2015 at the global, regional, and National level: results from the Global Burden of Disease Study 2015. Jama Oncol. 2017;3:1683-1691. doi:10.1001/jamaoncol.2017.3055 
6. Wang C, Jin H, Gao D, et al. phospho-ERK is a biomarker of response to a synthetic lethal drug combination of sorafenib and MEK inhibition in liver cancer. $J$ Hepatol. 2018. doi:10.1016/j. jhep.2018.07.004

7. Xie D, Yuan P, Wang D, et al. Expression and prognostic significance of miR-375 and miR-221 in liver cancer. Oncol Lett. 2017;14:2305-2309. doi:10.3892/ol.2017.6423

8. Wang Y, Xie Y, Li X, et al. MiR-876-5p acts as an inhibitor in hepatocellular carcinoma progression by targeting DNMT3A. Pathol Res Pract. 2018;214:1024-1030. doi:10.1016/j.prp.2018.04.012

9. Xian Q, Jing C, Long W, et al. MiR-30b-5p acts as a tumor suppressor, repressing cell proliferation and cell cycle in human hepatocellular carcinoma. Biomed Pharmacother. 2017;89:742. doi:10.1016/j. biopha.2017.02.062

10. Chamani F, Sadeghizadeh M, Masoumi M, et al. Evaluation of MiR-34 family and DNA methyltransferases 1, 3A, 3B gene expression levels in hepatocellular carcinoma following treatment with dendrosomal nanocurcumin. Asian Pac J Cancer Prev. 2016;17:219-224.

11. Zhen Z, Rui L, Sha S, et al. Targeting HER3 with miR-450b-3p suppresses breast cancer cells proliferation. Cancer Biol Ther. 2014;15:1404-1412. doi:10.4161/cbt.29923

12. Jin Y, Jiang Z, Guan X, et al. miR-450b-5p suppresses stemness and the development of chemoresistance by targeting SOX2 in colorectal cancer. DNA Cell Biol. 2016;35:249. doi:10.1089/dna.2015.3120

13. Hong J, Yao L, Zhang JR, et al. The expression and clinical significance of miR-450a-5p in serous ovarian cancer. Progress Mod Biomed. 2014;14:3240-3243.

14. Zhang ZW, Chen JJ, Xia SH, et al. Long intergenic non-protein coding RNA 319 aggravates lung adenocarcinoma carcinogenesis by modulating miR-450b-5p/EZH2. Gene. 2018;650:60-67. doi:10.1016/j.gene.2018.01.096

15. Weng Z, Wang D, Zhao W, et al. microRNA-450a targets DNA methyltransferase 3a in hepatocellular carcinoma. Exp Ther Med. 2011;2:951. doi:10.3892/etm.2011.288
16. Min L, Weng Y, Jian T, et al. MicroRNA-450a-3p represses cell proliferation and regulates embryo development by regulating Bub1 expression in mouse. PLoS One. 2012;7:e47914. doi:10.1371/journal. pone. 0047914

17. Liu C, Yang DD, Jiang FB, et al. MicroRNA-450a-3p regulates cell proliferation and embryonic development by repressing Bublgene in mouse. Chin J Pathophysiol. 2012;28:1651-1657.

18. Jia H, Xiaojuan L, Li Y, et al. The effect of miR-450a-5p on the biological behavior of serous ovarian cancer SKOV3 cells. J Mod Oncol. 2015;7:892-896. doi:10.3969/j.issn.1672-4992.2015.07.04.

19. Liu F, Yu X, Huang H, et al. Upregulation of microRNA-450 inhibits the progression of lung cancer in vitro and in vivo by targeting interferon regulatory factor 2. Int $J$ Mol Med. 2016;38:283. doi:10.3892/ijmm.2016.2650

20. Saito Y, Kanai Y, Sakamoto M, et al. Expression of mRNA for DNA methyltransferases and methyl-CpG-binding proteins and DNA methylation status on $\mathrm{CpG}$ islands and pericentromeric satellite regions during human hepatocarcinogenesis $\vec{s}$. Hepatology. 2001;33:561-568. doi:10.1053/jhep.2001.22507

21. Shikauchi Y, Saiura A, Kubo T, et al. SALL3 interacts with DNMT3A and shows the ability to inhibit CpG island methylation in hepatocellular carcinoma. Mol Cell Biol. 2009;29:1944-1958. doi:10.1128/MCB.00840-08

22. Wu Y, Bu F, Yu H, et al. Methylation of Septin9 mediated by DNMT3a enhances hepatic stellate cells activation and liver fibrogenesis. Toxicol Appl Pharmacol. 2017;315:35-49. doi:10.1016/ j.taap.2016.12.002

23. Zhao Z, Wu Q, Cheng J, et al. Depletion of DNMT3A suppressed cell proliferation and restored PTEN in hepatocellular carcinoma cell. $J$ Biomed Biotechnol. 2015;2010:737535.

24. Oh BK, Kim H, Park HJ, et al. DNA methyltransferase expression and DNA methylation in human hepatocellular carcinoma and their clinicopathological correlation. Int J Mol Med. 2007;20:65.
OncoTargets and Therapy

\section{Publish your work in this journal}

OncoTargets and Therapy is an international, peer-reviewed, open access journal focusing on the pathological basis of all cancers, potential targets for therapy and treatment protocols employed to improve the management of cancer patients. The journal also focuses on the impact of management programs and new therapeutic

\section{Dovepress}

agents and protocols on patient perspectives such as quality of life, adherence and satisfaction. The manuscript management system is completely online and includes a very quick and fair peer-review system, which is all easy to use. Visit http://www.dovepress.com/ testimonials.php to read real quotes from published authors. 